\title{
When everything damaged and we didn't know why
}

\section{Michael Bass}

Michael Bass, "When everything damaged and we didn't know why," Proc. SPIE 10805, Laser-Induced Damage in Optical Materials 2018: 50th Anniversary Conference, 1080504 (16 November 2018); doi: 10.1117/12.2503554

SPIE. Event: SPIE Laser Damage, 2018, Boulder, Colorado, United States 


\title{
When everything damaged and we didn't know why
}

\author{
Michael Bass \\ CREOL, The College of Optics and Photonics \\ University of Central Florida \\ Orlando, FL 32816
}

\begin{abstract}
This is a reminiscence of where things stood in the laser damage problem at the time when the laser reached its $10^{\text {th }}$ birthday. All of the different types of lasers that we know today had been demonstrated and those that could reach high power were shown to destroy the optics used in the resonators or to manipulate the high power beams. If high power lasers were to be useful the problem of laser damage had to be solved but first it had to be understood.
\end{abstract}

\section{SOME IMPORTANT DEFINITIONS}

It was necessary to set down some very hard and fast rules about how to specify a laser beam used in a damage experiment. You might think the quantities would be obvious but it wasn't too many years earlier that the energy in a pulsed laser output was being given by how many Gillette single edge razor blades it could drill through when focused with a specified lens. Calibrated (and maybe trustworthy) energy meters had only recently come on the market. Also, laser damage experiments were being reported using multimode lasers that can produce different spatial patterns from one pulse to the next. Such data could give rough guidelines to what power density caused damage but no insight that could lead to an understanding of what was actually happening.

The properties of the sample or surface being studied had to be prescribed including such non obvious matters such as how it was finished, what chemicals had been used in the polishing and cleaning, what was the atmospheric conditions of content, pressure, and temperature, how was the sample oriented and more. As a consequence I presented two tables in my first paper at the Boulder Damage Symposium specifying how to describe a laser pulse and how to describe a sample. These are shown below:

\begin{tabular}{|l|l|}
\hline & Table I - Parameters Necessary to Characterize a Pulse of Laser Light \\
\hline 1 & Wavelength, $\lambda$, and spectral width, $\Delta \lambda$ \\
\hline 2 & Energy in joules \\
\hline 3 & Pulse duration \\
\hline 4 & Transverse mode pattern \\
\hline 5 & Longitudinal mode content \\
\hline 6 & Beam's transverse dimension at the surface \\
\hline 7 & Position of focal point if any or the beam waist \\
\hline 8 & Polarization state \\
\hline 9 & Pulse repetition rate \\
\hline
\end{tabular}




\begin{tabular}{|l|l|}
\hline & Table II - Parameters Necessary to Characterize a Crystalline Surface \\
\hline 1 & Name of the crystal \\
\hline 2 & Cleaved or polished surface \\
\hline 3 & Flatness \\
\hline 4 & Smoothness \\
\hline 5 & Cleanliness \\
\hline 6 & $\begin{array}{l}\text { Orientation of the crystallographic axes with respect to the light beam propagation } \\
\text { and electric field vectors }\end{array}$ \\
\hline 7 & Temperature \\
\hline 8 & Atmosphere above surface \\
\hline
\end{tabular}

While it may seem obvious that the quantities in Tables I and II were necessary it was not so 50 years ago. Then too it was not obvious to all concerned what was meant by the words "damage threshold". Some of the experiments done with multimode laser beams resulted in answers that varied from one pulse to the next. This was caused by experiments that were too rushed. They suggested that the so-called threshold was not a well-defined power density. Either that or the material or surface was not uniform enough to have a sharp threshold. As a consequence I took it on myself to define the highest power density that never produced damage as $P_{\infty}$ and the lowest power density that always produced damage on a single pulse as $P_{1}$. If these two were equal then there was a well-defined damage threshold. If not the experimenter had to first determine if there was some experimental cause or if the dependence of the number of pulses required to produce damage on power density between $P_{\infty}$ and $P_{1}$ was a property of the damage mechanism.

It may seem unnecessary today to spell out how to decide when damage took place but back then it was. In my work I settled on an observer viewing the irradiated spot on the sample through a microscope with 200x magnification. The microscope was fitted with a reflector and filter that protected the observer from the $1064 \mathrm{~nm}$ laser light used. When the observer saw something on the surface following irradiation damage had happened. The experiments demonstrated that physical damage to the sample was always observed following observation of a spark or breakdown during the irradiation. When the sample was not present and for $\mathrm{P}>P_{1}$ no spark in air could be detected. These observations and the fact that $P_{\infty}$ and $P_{1}$ were in almost all cases studied not equal led us to investigate electron avalanche breakdown as the cause of laser induced damage.

These first two papers at the Boulder Laser Damage Conference dealt with damage to non-linear crystals. That came about because a year or two before while studying dye lasers we noticed that the dye powders gave off green light when struck by a beam of Nd:YAG laser light. With help from colleagues at Raytheon we grew crystals of these materials and published an Applied Physics Letters paper on the nonlinear properties of organic dye crystals. One property that they seemed to show was high damage threshold. This caught the interest of Martin Stickley at the Air Force Cambridge Research Laboratory who contacted me about exploring the damage properties of non-linear 
materials. He helped find funding for such work and the rest is history. I was able to continue studying the damage phenomenon for many years. Martin became a sponsor, colleague and friend.

In other work with $\sim 10$ nsec Q-Switched Nd:YAG laser pulses I had observed that the laser induced breakdown completely blocked the laser light in less than $1 \mathrm{nsec}$. This was the response time of the detector-oscilloscope that I had. Then, in 1977 I had the opportunity to work with a former student from USC, John Anthes, who was at Sandia. He had a picosecond pulse Nd laser system and a picosecond response time streak camera. We frequency doubled the laser pulse to be in the green where the camera was responsive. Then we monitored the transmitted pulse waveform when no damage was produced in ultraviolet grade fused quartz and then when it was. We were able to show that the breakdown that resulted completely blocked the $532 \mathrm{~nm}$ light in less than $6 \mathrm{psec}$ and it dissipated in less than 6 psec. $6 \mathrm{psec}$ was the time resolution of the streak camera. I expect that with shorter duration laser pulses and more elaborate means of monitoring the properties of the induced breakdown the dynamics of laser induced breakdown can be explored further.

I had the good fortune of working on laser damage problems with colleagues H. H. Barrett and D. Bua while I was at the Raytheon Research Division. While I was at USC I worked with students M. J. Soileau and S. T. Wu, and Post-Doc, Eric Vanstryland who would become colleagues at CREOL, The College of Optics and Photonics at UCF. 